\title{
HAZARD PERCEPTION AND DISTRACTION IN NOVICE DRIVERS: EFFECTS OF 12 MONTHS DRIVING EXPERIENCE
}

\author{
Anuj Pradhan ${ }^{1}$, Bruce Simons-Morton ${ }^{1}$, Suzanne Lee ${ }^{2}$, \& Sheila Klauer ${ }^{2}$ \\ ${ }^{1}$ National Institute of Child Health and Human Development, Bethesda, Maryland, USA \\ ${ }^{2}$ Virginia Tech Transportation Institute (VTTI), Blacksburg, Virginia, USA \\ Email: anuj.pradhan@nih.gov
}

\begin{abstract}
Summary: The high crash risk of novice drivers has been partly attributed to their underdeveloped hazard perception abilities. Novice drivers also have an increased risk of crashes due to distractions. Studies show that novice drivers do not detect risk relevant cues and are more susceptible to distractions when compared to adult drivers. This test track study was conducted to study the effects of 12 months of driving experience on teenagers. Forty-two teenagers and their parents drove through hazard perception scenarios while engaged in secondary tasks. These participants had participated in a similar session 12 months earlier. For the odometer and texting task conditions the novice drivers showed an improvement in hazard perception and a small but insignificant decrease in task suspension after 12 months. For the scenario with the cell phone task none of the novice drivers suspended the task, nor exhibited any sort of hazard perception behavior at 12 months. The results indicate that although hazard perception generally improves with experience under some distracting task conditions this is not the case for cell phone distractions.
\end{abstract}

\section{OBJECTIVE}

Novice drivers are overrepresented in vehicle crashes compared to experienced drivers (IIHS, 2009). Sixteen-year-old drivers have the highest crash rate among teenage drivers (Ferguson et al., 2007), more so for the first 6 months of driving and 1000 miles after licensure (Mayhew et al., 2003). McKnight and McKnight (2003) identified the failure of appropriate visual search as a leading cause for crashes in a review of 1000 crashes. This failure to search appropriately results in poor hazard perception in novices as compared to experienced drivers (Pradhan et al., 2005; Chapman et al., 2002). An increase in reported secondary task engagement (Lerner \& Boyd, 2005) further compounds the safety factors affecting novices. Secondary tasks have been shown to degrade driving performance (Strayer et al, 2003), particularly in novice drivers as evidenced in crash reports (McKnight and McKnight, 2003), and simulator (Greenberg et al., 2003), naturalistic (Klauer et al., 2006), and test track studies (Olsen et al., 2006).

This study examines the effects of 12 months of driving experience on various teen driver behaviors. Lee et al. (2008) compared hazard perception between newly licensed teens and experienced adults on a test-track and reported significantly better hazard perception behavior in adults. Olsen et al. (2006) reported that 6 months of driving experience for teen drivers did not result in significant improvements on intersection related tasks. This current study extends their findings by bringing back the participants from Lee et al. (2008) to the test track after 12 months to study changes in hazard perception and secondary task engagement behavior. 


\section{METHODS}

\section{Participants}

All participants of the 40-car naturalistic teen driving study conducted at VTTI were enlisted resulting in two groups: 42 newly licensed drivers (mean age of 16.5 years at time $\mathrm{T}_{0}$ ), and 42 experienced adult drivers (mean age of 47.2 years at time $\mathrm{T}_{0}$ ). The experienced group comprised of one respective parent of each teen. Each driver undertook two 90 -minute sessions $\left(\mathrm{T}_{0} \& \mathrm{~T}_{12}\right)$ 12 months apart. The teen and adult groups had $49 \%$ and $68 \%$ female drivers respectively. All drivers had at least 20/40 corrected vision and were licensed to drive in the USA.

\section{Apparatus}

Test track. The Virginia Tech Transportation Institute’s (VTTI) Smart Road is a 2.2 mile, controlled-access closed-course system with a two lane highway. The track contains a signalized intersection controlled by a Dedicated Short Range Communication (DSRC) unit.

Instrumented vehicle. The test vehicle was a 1997 Ford Taurus with standard safety equipment and an emergency passenger side brake. A Data Acquisition System (DAS) recorded vehicle parameters and video feed. Four in-vehicle cameras recorded views of the driver's face, out the windshield, the pedals, and over the driver's shoulder.

\section{Procedure}

Before driving the participants were familiarized with the test vehicle, the secondary task devices, and the secondary tasks. They were asked to obey all traffic regulations and exercise normal road safety. They were also informed that the only vehicles on the test track would be their vehicle, a lead vehicle, and a road maintenance crew's van. The latter two were actually driven by confederates and the van was used to stage scenarios. Two experimenters were always in the test vehicle, one in the passenger seat providing instructions and one in the rear handling experimental protocol. Specific instructions were given for the secondary task for a particular scenario while the participant was driving and just prior to entering the scenario.

Each participant drove seven laps in the test track. The trials were designed such that each half of a lap contained one specific combination of secondary task and driving scenario. The laps and secondary tasks were counterbalanced using two sets of lap orders and secondary task presentation orders. A comprehensive report of the apparatus, procedure, and scenarios is detailed at Howard (2010).

\section{Scenarios}

The seven laps in the test track were designed to yield 14 unique secondary tasks/scenario combinations at three different speeding levels (Howard, 2010). Of these, this paper will discuss four that cover a combination of three secondary tasks and three hazard perception scenarios. 
1. Hidden hazard (Stop sign)/Odometer task. The drivers were asked to monitor the odometer and report whenever the last digit showed a 3, 6 or a 9. They drove through the signalized intersection, except that the signals were inactive and the lights dark. During their approach a van parked on the right shoulder, just before the intersection, obscured the view of a stop sign placed in front of it until they was about 50 feet from it. The variables recorded were whether the drivers looked at the stop sign, if they stopped at the sign, and if they did not stop whether they showed signs of late recognition as shown by facial expressions, comments, or foot movements.

2. Hidden hazard (Pedestrian)/Odometer task. A van was parked on the right shoulder with the rear doors open and a confederate posing as a maintenance worker behind it. As the driver approached the confederate closed the doors and walked around the van from the passenger side. As the driver passed the van the confederate walked across its front but did not cross the road. The variables recorded were whether the drivers looked for the pedestrian as they passed the van, and whether they displayed any behavior indicating caution.

3. Hidden hazard (Pedestrian)/Texting task. The drivers were asked to use the provided phone to send text messages while driving. The experimenter provided the recipient's phone number and the message contents. This scenario was staged much like the second one described above except the van was parked on the right lane instead of the shoulder and a set of traffic cones closed off the right lane. The confederate performed the same actions as in the previous scenario. The variables recorded were whether the drivers looked for the pedestrian, if they displayed behavior indicating caution, and if they suspended the task while passing the scenario.

4. Hidden Hazard (Animal)/Cell phone Task. The drivers were asked to use a hand-held cell phone to dial the 511 traffic information service that contains recorded real time updates on local traffic incidents on major roadways. They were asked to listen and to verbally report certain incidents. This scenario was staged like the third one described above, but instead of the confederate walking around the van, a large stuffed dog was placed at the front, obscured from the drivers until they passed the van. The variables recorded were whether the drivers looked at the animal, whether they showed signs of caution, and whether they suspended the task.

The variables were coded from the videos and experimenter notes by trained reductionists following a protocol for scoring subjective measures, with an inter rater reliability of over 95\%.

\section{RESULTS}

The aims of this study were (a) to study change in hazard perception behavior of teen drivers engaged in secondary tasks between the times when they had just started driving and after they gained 12 months of driving experience, and (b) to study the secondary task engagement behavior of these drivers between the two times.

Analyses were conducted to study changes in the teenage group's hazard perception and secondary task engagement after 12 months of experience. The analyses were done using McNemar's Test given the matched pairs and dichotomous variables (Table 1 and Figure 1). 
PROCEEDINGS of the Sixth International Driving Symposium on Human Factors in Driver Assessment, Training and Vehicle Design

Table 1. Hazard perception and secondary tasks in teens - month 0 vs. month 12

\begin{tabular}{|c|c|c|c|c|c|c|c|c|c|c|c|c|}
\hline \multirow[b]{2}{*}{$\begin{array}{l}\text { Scenario/ } \\
\text { Task }\end{array}$} & \multicolumn{3}{|c|}{ Stopped? } & \multicolumn{3}{|c|}{ Looked at Hazard? } & \multicolumn{3}{|c|}{ Signs of caution? } & \multicolumn{3}{|c|}{ Suspended task? } \\
\hline & $\mathrm{T}_{0}$ & $\mathrm{~T}_{12}$ & $p$ & $\mathrm{~T}_{0}$ & $\mathrm{~T}_{12}$ & $p$ & $\mathrm{~T}_{0}$ & $\mathrm{~T}_{12}$ & $p$ & $\mathrm{~T}_{0}$ & $\mathrm{~T}_{12}$ & $p$ \\
\hline 1 & $27.8 \%$ & $58.3 \%$ & $<0.01$ & $50.0 \%$ & $77.8 \%$ & $<0.01$ & $15.4 \%$ & $53.8 \%$ & 0.125 & & N/A & \\
\hline 2 & & $\mathrm{~N} / \mathrm{A}$ & & $11.4 \%$ & $37.1 \%$ & $<0.01$ & $19.4 \%$ & $50.0 \%$ & $<0.05$ & & N/A & \\
\hline 3 & & N/A & & $15.4 \%$ & $33.3 \%$ & 0.065 & $7.7 \%$ & $33.3 \%$ & $<0.01$ & $62.5 \%$ & $43.8 \%$ & 0.179 \\
\hline 4 & & N/A & & $12.8 \%$ & $0.0 \%$ & 0.06 & $2.6 \%$ & $0.0 \%$ & 1.00 & $7.7 \%$ & $0.0 \%$ & 0.25 \\
\hline
\end{tabular}

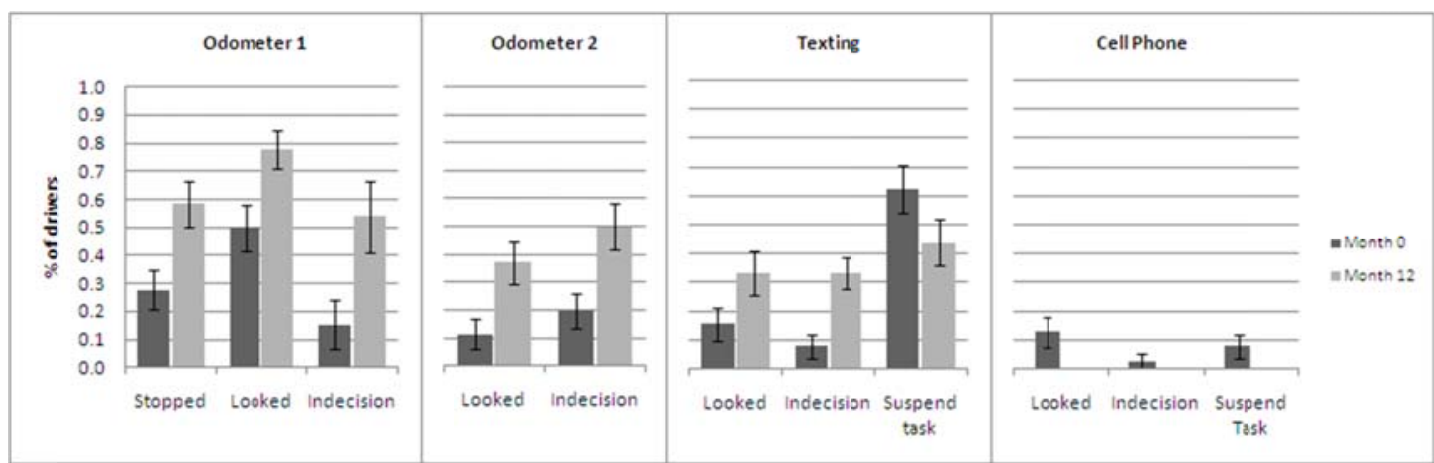

Figure 1. Hazard perception and secondary tasks in teens - month 0 vs. month 12 (error bars are SEM)

Lee et al (2008) found that at $\mathrm{T}_{0}$, for the first three scenarios, more adults looked towards the hidden hazards or displayed caution, but were not significantly different in task suspension than teenagers. However no such prior comparisons existed for the cell phone task, so differences between groups were analyzed at $\mathrm{T}_{0}$ and $\mathrm{T}_{12}$ using Fisher's Exact Test (Table 2).

Table 2. Hazard perception and secondary tasks in teens vs. adults - month 0 and month 12

\begin{tabular}{lccccccc}
\hline \multirow{2}{*}{ Task/Scenario 4 (Cell phone) } & \multicolumn{3}{c}{$\mathrm{T}_{0}$} & \multicolumn{3}{c}{$\mathrm{T}_{12}$} \\
\cline { 2 - 7 } & Teen & Adult & $p$ & Teen & Adult & $p$ \\
\hline Looked at hazard? & $12.5 \%$ & $12.2 \%$ & 1 & $0.0 \%$ & $9.1 \%$ & 0.117 \\
Signs of caution? & $2.5 \%$ & $12.2 \%$ & 0.201 & $0.0 \%$ & $5.0 \%$ & 0.24 \\
Suspended task? & $7.5 \%$ & $4.9 \%$ & $\mathbf{0 . 6 7 5}$ & $0.0 \%$ & $7.5 \%$ & 0.115 \\
\hline
\end{tabular}

Analyses were also done for all scenarios for (1) differences in hazard perception behavior of adults between $T_{0}$ and $T_{12}$, and (2) differences between the two groups at $T_{12}$. For the first, in all but one of the variables, there were no significant differences after 12 months. However, in the third scenario adults showed more caution at $\mathrm{T}_{12}$ than at $\mathrm{T}_{0}(49 \%$ vs. $15 \%, \mathrm{p}<0.01)$. For the second, more adults had appropriate hazard perception behaviors in all scenarios at $\mathrm{T}_{12}$. These were however significant for just two variables, both in the first scenario: 'looked at stop sign', 95\% vs. 79\%, p < 0.05; and, 'signs of indecision', 92\% vs. 50\%, p $<0.05$.

\section{CONCLUSION}

Except for the cell phone task, the results show an improvement in hazard perception behavior in teenagers after 12 months of driving experience. These improvements are in line with studies 
that show the effect of experience on hazard perception (Pradhan et al, 2005; Underwood et al, 2003). This improvement closes the gap between the adults and teenagers at time $T_{12}$ such that the differences between the two groups are considerably reduced as compared at $\mathrm{T}_{0}$ (Lee et al, 2008). The adults do not differ significantly between $T_{0}$ and $T_{12}$ indicating that potential learning or carryover effects did not persist between time periods. With respect to task suspension however, there were no improvements in task suspension rates for the teenage group. In fact there actually was a decrease in the task suspension rates at time $\mathrm{T}_{12}$ for both the secondary tasks.

These results for task suspension rates and corresponding hazard perception scores across time are interesting. For the texting task $37 \%$ of the teenagers did not suspend the task at $\mathrm{T}_{0}$, and this increased to $56 \%$ at $\mathrm{T}_{12}$. For the cell phone task, $92 \%$ of the teenagers did not suspend the task during $\mathrm{T}_{0}$, and this increased to $100 \%$ at $\mathrm{T}_{12}$. However, during the texting task there was an increase in the teenagers' looks towards the hazard: 15\% (at $\mathrm{T}_{0}$ ) and 33\% (at $\mathrm{T}_{12}$ ). During the cell phone task, there was a decrease: $12 \%\left(\right.$ at $\left.\mathrm{T}_{0}\right)$ and $0 \%\left(\right.$ at $\left.\mathrm{T}_{12}\right)$.

The higher task suspension rates for the texting task seem to indicate more awareness of the distraction inherent in that task, given the necessity of looking away from the forward roadway while texting. This awareness may thus result in more efforts at scanning the forward roadway for hazards, as evidenced by more task suspensions and more looks towards potential hazards. The cell phone task, on the other hand, may lead the driver to be under the false impression that they are able to detect any hazards on the roadway, especially since their eyes are not off the forward roadway during the task. This misplaced confidence could be the cause of the very low task suspension rates, and the equally small number of looks at the potential hazards.

The very low task suspension rates during the cell phone task for experienced drivers at $\mathrm{T}_{0}$ and at $\mathrm{T}_{12}$ show that this isn't a problem faced by novice drivers alone. In fact there is evidence of both novice and experienced drivers making extended glances away from the forward roadway during tasks where they may feel they are sufficiently able to monitor the forward roadway while engaged in the task (Chan et al, 2010). Studies of inattentional blindness (Simons and Chabris, 1999) in general and during driving (Strayer et al, 2003) could also explain this false confidence in drivers during secondary tasks that don't require taking their eyes off the road.

The decrease in task suspension rates for the teenagers may be a result of changes in visual search as a result of different cognitive loading, or perhaps an increased allocation of resources to secondary tasks due to perceived improvement in vehicle handling skills or self-confidence (Lerner \& Boyd, 2005) in teenagers after a year's experience. Further analyses, particularly involving driver eye movements during the secondary task engagement, are warranted for studying these dynamics of distraction and hazard perception for teenage drivers.

\section{ACKNOWLEDGEMENTS}

This research was supported by the Intramural Research Program of the NIH Eunice Kennedy Shriver National Institute of Child Health and Human Development. The authors thank Jennifer Mullen and others of VTTI for their expertise and assistance in data collection and reduction. 


\section{REFERENCES}

Chan, E., Pradhan, A. K., Pollatsek, A., Knodler, M. A., Fisher, D. L. (2010). Are driving simulators effective tools for evaluating novice drivers' hazard anticipation, speed management, and attention maintenance skills? Transportation Research F, 13, 343-353.

Chapman, P., Underwood, G., and Roberts, K. (2002). Visual search patterns in trained and untrained novice drivers. Transportation Research F, 5, 157-167.

Ferguson, S., Teoh, E., and McCartt, A. (2007). Progress in teenage crash risk during the last decade. Journal of Safety Research, 38, 137-145.

Greenberg, J., Tijerina, L., Curry, R., Artz, B., Cathey, L., Grant, P., Kochhar, K., Kozak, K., Blommer, M. (2003). Evaluation of driver distraction using an event detection paradigm. Presented at $82^{\text {nd }}$ Annual Meeting of the Transportation Research Board, Washington , D.C.

Howard, E. H., (2010). Examining the effect of driving experience on teenage driving ability with secondary tasks on a closed track. Master's Thesis, Virginia Polytechnic Institute and State University, Blacksburg, Virginia.

Insurance Institute for Highway Safety (2009). Fatality Facts, Teenagers. http://www.iihs.org/research/ fatality_facts_2009/teenagers.html. Last accessed, December 2, 2010. Arlington, VA.

Klauer, S. G., Dingus, T. A., Neale, V. L., Sudweeks, J. D., \& Ramsey, D. J. (2006). The impact of driver inattention on near-crash/crash risk: An analysis using the 100-car naturalistic driving study data. National Highway Traffic Safety Administration, Washington, D.C.

Lee, S. E., Klauer, S. G., Olsen, E. C. B., Simons-Morton, B. G., Dingus, T. A., Ramsey, D. J., Ouimet, M. C. (2008). Detection of road hazards by novice teen and experienced adult drivers. Transportation Research Record, 2078, 26-32.

Lerner N., and Boyd, S. (2005). Task Report: On-road study of willingness to engage in distracting tasks. Report jointly funded under National Highway Safety Administration (Contract DTNH22-99-D-07005, Task Order Number 7) and National Institute of Child Health and Human Development (Contract GS-23F-8144H). Westat, Rockville: MD.

Mayhew, D. R., Simpson, H. M., and Pak, A. (2003). Changes in collision rates among novice drivers during the first months of driving. Accident Analysis and Prevention, 35 (5), 683-691.

McKnight, J. A. and McKnight, S. A. (2003). Young novice drivers: careless or clueless. Accident Analysis and Prevention, 35, 921-925.

Olsen, E. C. B., Simons-Morton, B. G., \& Lee, S. E. (2006). Novice teen and experienced adult drivers on the smart road intersection: Does six months of experience matter? Proceedings of the Human Factors \& Ergonomics Society $50^{\text {th }}$ Annual Meeting, October 2006, San Francisco.

Pradhan, A. K., Hammel, K. R., DeRamus, R., Pollatsek, A., Noyce, D. A., Fisher, D. L. (2005). Using eye movements to evaluate the effects of driver age on risk perception in a driving simulator. Human Factors, 47 (4), 840-852.

Simons, D.J.; Chabris, C.F. (1999). "Gorillas in our midst: sustained inattentional blindness for dynamic events". Perception 28 (9): 1059-1074. 
Strayer, D. L., Drews, F. A., and Johnston, W. A. (2003). Cell phone-induced failures of visual attention during simulated driving. Journal of Experimental Psychology, 9 (1), 23-32.

Underwood, G., Chapman, P., Brocklehurst, N., Underwood, J., Crundall, D. (2003). Visual attention while driving: Sequences of eye fixations made by experienced and novice drivers. Ergonomics, 46(6), 629-646. 